Review Article

\title{
Nonalcoholic Fatty Liver Disease and Cardiovascular Diseases: The Heart of the Matter
}

\author{
Stefan Chiriac $\left(\mathbb{D},{ }^{1,2}\right.$ Carol Stanciu $\left(\mathbb{D},{ }^{2}\right.$ Irina Girleanu $\left(D,{ }^{1,2}\right.$ Camelia Cojocariu $\left(D,{ }^{1,2}\right.$ \\ Catalin Sfarti (D), ${ }^{1,2}$ Ana-Maria Singeap $\mathbb{D}^{1},{ }^{1,2}$ Tudor Cuciureanu (D), ${ }^{1}$ Laura Huiban (D), \\ Cristina Maria Muzica $\mathbb{D}^{1},{ }^{1}$ Sebastian Zenovia $\mathbb{D}^{1},{ }^{1}$ Robert Nastasa, ${ }^{1}$ and Anca Trifan $\mathbb{D}^{1,2}$ \\ ${ }^{1}$ Department of Gastroenterology, “Grigore T. Popa” University of Medicine and Pharmacy, Iasi 700115, Romania \\ ${ }^{2}$ Institute of Gastroenterology and Hepatology, "St. Spiridon” Emergency Hospital, Iasi 700111, Romania \\ Correspondence should be addressed to Irina Girleanu; gilda_iri25@yahoo.com
}

Received 20 November 2020; Revised 16 December 2020; Accepted 21 December 2020; Published 12 January 2021

Academic Editor: Branka Filipović

Copyright (C) 2021 Stefan Chiriac et al. This is an open access article distributed under the Creative Commons Attribution License, which permits unrestricted use, distribution, and reproduction in any medium, provided the original work is properly cited.

\begin{abstract}
Nonalcoholic fatty liver disease (NAFLD) has emerged as the most frequent cause of liver disease worldwide, comprising a plethora of conditions, ranging from steatosis to end-stage liver disease. Cardiovascular disease (CVD) has been associated with NAFLD and CVD-related events represent the main cause of death in patients with NAFLD, surpassing liver-related mortality. This association is not surprising as NAFLD has been considered a part of the metabolic syndrome and has been related to numerous CVD risk factors, namely, insulin resistance, abdominal obesity, dyslipidemia, hyperuricemia, chronic kidney disease, and type 2 diabetes. Moreover, both NAFLD and CVD present similar pathophysiological mechanisms, such as increased visceral adiposity, altered lipid metabolism, increased oxidative stress, and systemic inflammation that could explain their association. Whether NAFLD increases the risk for CVD or these diagnostic entities represent distinct manifestations of the metabolic syndrome has not yet been clarified. This review focuses on the relation between NAFLD and the spectrum of CVD, considering the pathophysiological mechanisms, risk factors, current evidence, and future directions.
\end{abstract}

\section{Introduction}

In the last decades, the prevalence of nonalcoholic liver disease (NAFLD) has been rapidly increasing [1]. NAFLD affects from 25 to $45 \%$ of the general adult population and up to $70 \%$ of type 2 diabetic patients in Europe and North America [2]. Nonalcoholic steatohepatitis (NASH) is a subtype of NAFLD characterized by progressive liver disease that can lead to liver cirrhosis and hepatocellular carcinoma. Most of the patients with NAFLD develop mild disease, although $20-30 \%$ of them progress to NASH [2]. Approximately $20 \%$ of the patients with NASH and progressive fibrosis will develop liver cirrhosis with an increased risk of hepatocellular carcinoma [3-5].

NAFLD is associated with multiple extrahepatic diseases ranging from mild to severe organ-specific-related complications. Patients with NAFLD usually associate features of metabolic syndrome (MetS) which overlaps with the cardiovascular risk factors. All these factors are involved in the development of cardiovascular events (CVEs), which are the most common causes of death among these patients [6]. Several prospective and retrospective studies confirmed the association between NAFLD and cardiovascular diseases (CVD), with a negative impact on patients' outcome [7, 8].

All these studies have investigated the association between NAFLD and CVD, and efforts have been made to establish a direct relationship between these two complex conditions. However, as both are multifactorial diseases sharing common risk factors, a direct causality relation between NAFLD and the development of CVD has not yet been firmly established [9]. Of note, a previous meta-analysis demonstrated that the risk of developing a CVEe is $64 \%$ higher in patients with vs. without NAFLD [10]. The method of NAFLD diagnosis (ultrasound or computed tomography) was the main limitation of the studies included in this metaanalysis. The lack of a histologically proven diagnosis of 
NAFLD in the cross-sectional studies regarding cardiovascular involvement maintains the controversy on whether NAFLD is an active contributor or an innocent bystander in CVD development.

The complex physiopathology of both diseases with common risk factors and simultaneous involvement of different pathways makes it difficult to draw a clear conclusion regarding the direct relationship between NAFLD and CVD. Whether NAFLD confers any additional CVD risk, or whether an increase in CVD risk in NAFLD is due to associated CVD risk factors, is still uncertain. Confirming if NAFLD contributes as an independent CVD risk factor is important, as it is plausible that treatment of liver disease may decrease the CVD risk.

The aim of this review is to provide an update on the clinical evidence that supports the association between NAFLD and CVD, the impact on disease outcome, the main pathophysiological mechanism, and the most common cardiovascular comorbidities.

\section{Pathophysiology of Cardiovascular Involvement in NAFLD}

The pathophysiology behind the association of NAFLD with CVD is still incompletely understood and may involve other pathways besidesinsulin resistance (IR), such as oxidative stress, inflammation, and gut microbiota (Figure 1).

Abnormal glucose metabolism and hepatic IR are the major hallmarks of NAFLD, and they are the main elements in NAFLD and CVD pathogenesis [11-13]. The glucose metabolism disorders in NAFLD are secondary to the underlying systemic inflammation, visceral adiposity, and ectopic fatty tissue $[14,15]$. The IR is associated with hyperinsulinemia that determines increase in hepatic glucose production and chronic hyperglycemia. Persistent hyperglycemia and IR promote oxidative stress, activation of inflammation, and dysregulation of lipoprotein metabolism [14, 16, 17]. IR promotes oxidative stress and activation of inflammatory signaling pathways, vascular inflammation, and dysregulation of lipids metabolism contributing to ectopic fat accumulation [14, 18, 19]. Pancreatic ectopic adipose tissue is also associated with IR and beta cell dysfunction, hyperinsulinemia, and secondary increase of free fatty acid level. Hyperinsulinemia and the decrease of hepatic insulin clearance secondary to NAFLD are associated with increased hepatic gluconeogenesis, hyperglycemia, and insulin overproduction, a pathological self-reinforcing cycle. Insulin, as a catabolic hormone, increases the production of various lipogenic enzymes by activating transcription factors as carbohydrate-responsive element binding protein (ChREBP) or sterol regulatory element-binding proteins 1c (SREBP-1c) [20]. The consequence is further accumulation of hepatic fat, overproduction of VLDL particles, and increasing the vascular atherogenetic process.

Atherogenic dyslipidemia associated with NAFLD is the consequence of increased de novo hepatic lipogenesis along with an elevated rate of lipid uptake, both mechanisms determining the overproduction and secretion of large triglyceride-enriched VLDL particles, including apolipoprotein C3 (ApoC3) and apolipoprotein B (ApoB). The atherogenic dyslipidemia is characterized by high serum triglycerides, low high-density lipoprotein (HDL) cholesterol, the predominance of small dense low-density lipoprotein (LDL) particles, and increased intermediate-density lipoprotein (IDL) $[14,21]$. The atherogenic lipoproteins penetrate the vascular wall and activate the toll-like receptors (TLRs). These receptors sense the endogen damage signals and activate an immune response [22]. Activation of TLRs 2 and 4 receptors has a primary impact on activation of NODlike receptor family, pyrin domain-containing protein 3 (NLRP3) inflammasome [14, 23]. NLRP3 inflammasome regulates the activity of enzyme caspase-1, known as interleukin (IL)- $1 \beta$ converting enzyme [24]. This complex mechanism leads to the activation of proinflammatory cytokines as IL- $1 \beta$, IL- 6 , and C-reactive protein (CRP), all of them being involved in vascular inflammation and promoting atherosclerotic cardiovascular disease [24]. NAFLD patients have also an increased level of palmitic acid, incorporated in VLDL, and this saturated fatty acid also induces vascular inflammation by activating TLRs 2 and 4 $[14,25]$.

Endothelial dysfunction is one of the most important pathophysiological links between NAFLD and cardiovascular diseases. The oxidative stress and lipoprotein-mediated vascular inflammation are related to endothelial dysfunction that is characterized by decreased bioavailability of the nitric oxide (NO) $[14,23,26,27]$. There are two main factors contributing to endothelial dysfunction in NAFLD patients: low NO availability and hyperhomocysteinemia. It was demonstrated that patients with NAFLD have a low level of asymmetric dimethyl arginine (ADMA) determined by decreased liver breakdown of this molecule. ADMA is an endogenous antagonist of nitric oxide synthase (NOs) and its elevation is associated with decreased NO. Hyperhomocysteinemia induces oxidative stress by reduced glutathione stores in direct relation with low levels of NO. All these endothelial abnormalities increase platelet activation and vascular resistance [28-30].

In patients with NAFLD, an imbalanced coagulation cascade was demonstrated, and these subjects are being prone to a hypercoagulable state due to high levels of coagulation factors FVIII, FIX, FXI, FXII, fibrinogen, von Willebrand factor, and plasminogen activator inhibitor-1, along with low levels of anticoagulant factors as antithrombin III and protein C [12, 26, 30].

Recently, the hepatokines have been demonstrated to be potential mediators of cardiometabolic syndrome in NAFLD [31]. Of these, fetuin A was associated with CVD [32]. The experimental studies have demonstrated that fetuin $\mathrm{A}$ induces low-grade inflammation in concert with fatty acids [33].

Fat accumulation in the liver could be associated with ectopic fatty tissue, including myocardial fat and adipose tissue surrounding the heart, a central aspect of the relationship between NAFLD and CVD [34]. Under physiological conditions, this adipose tissue has anti-inflammatory and antifibrotic proprieties $[35,36]$. In NAFLD, the systemic 
Geneic factors
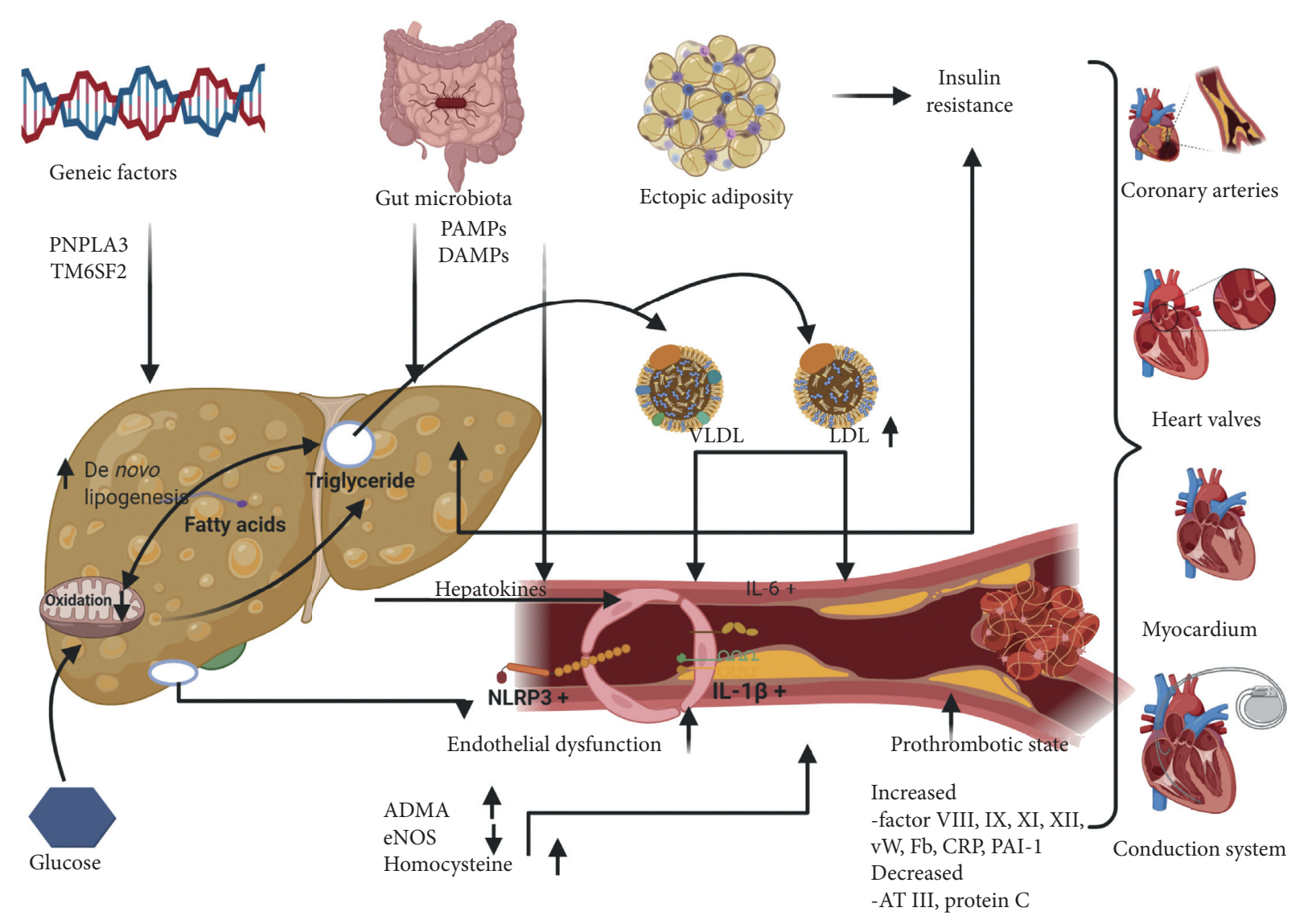

Gut microbiota PAMPS

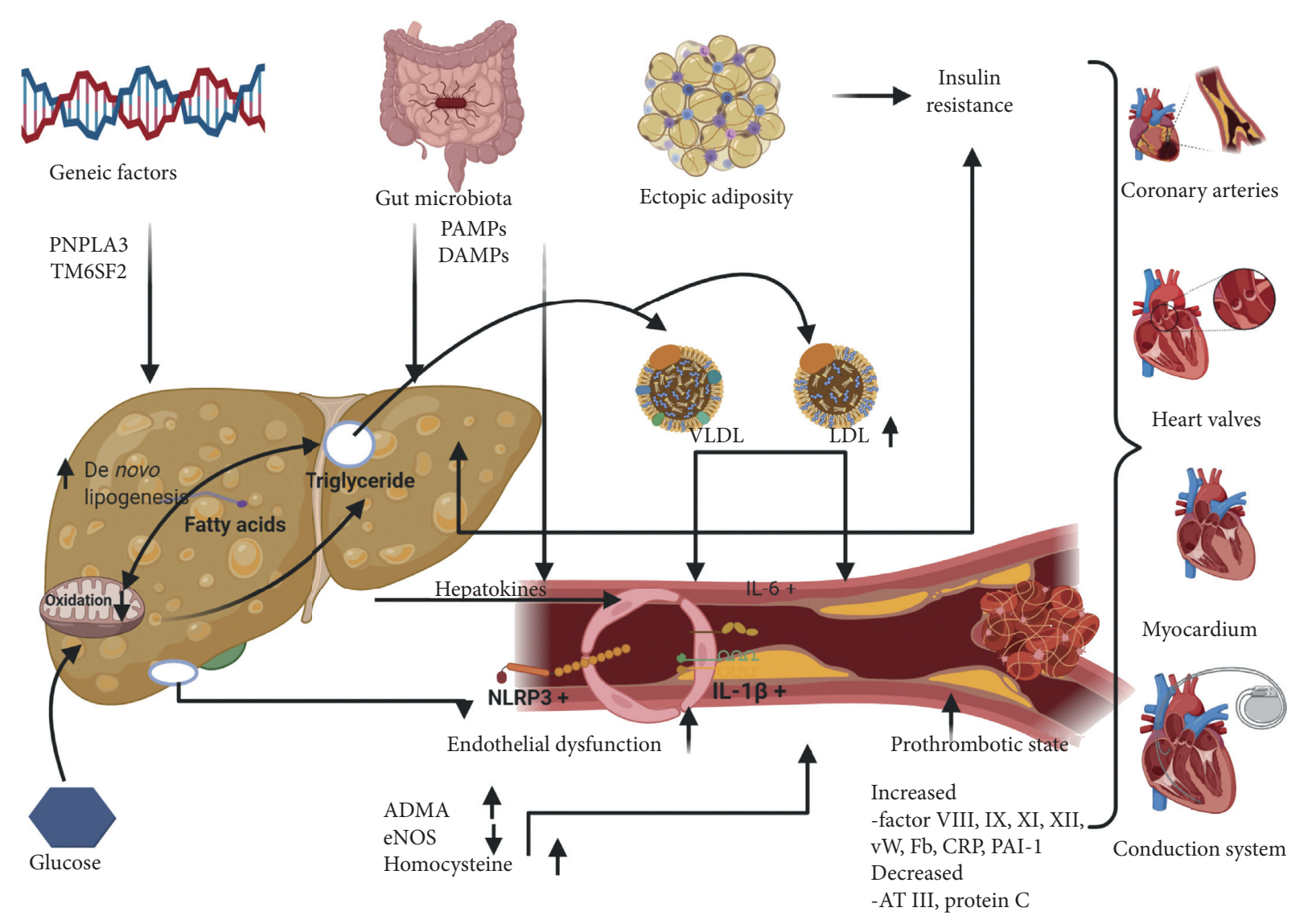

ctopic adiposity

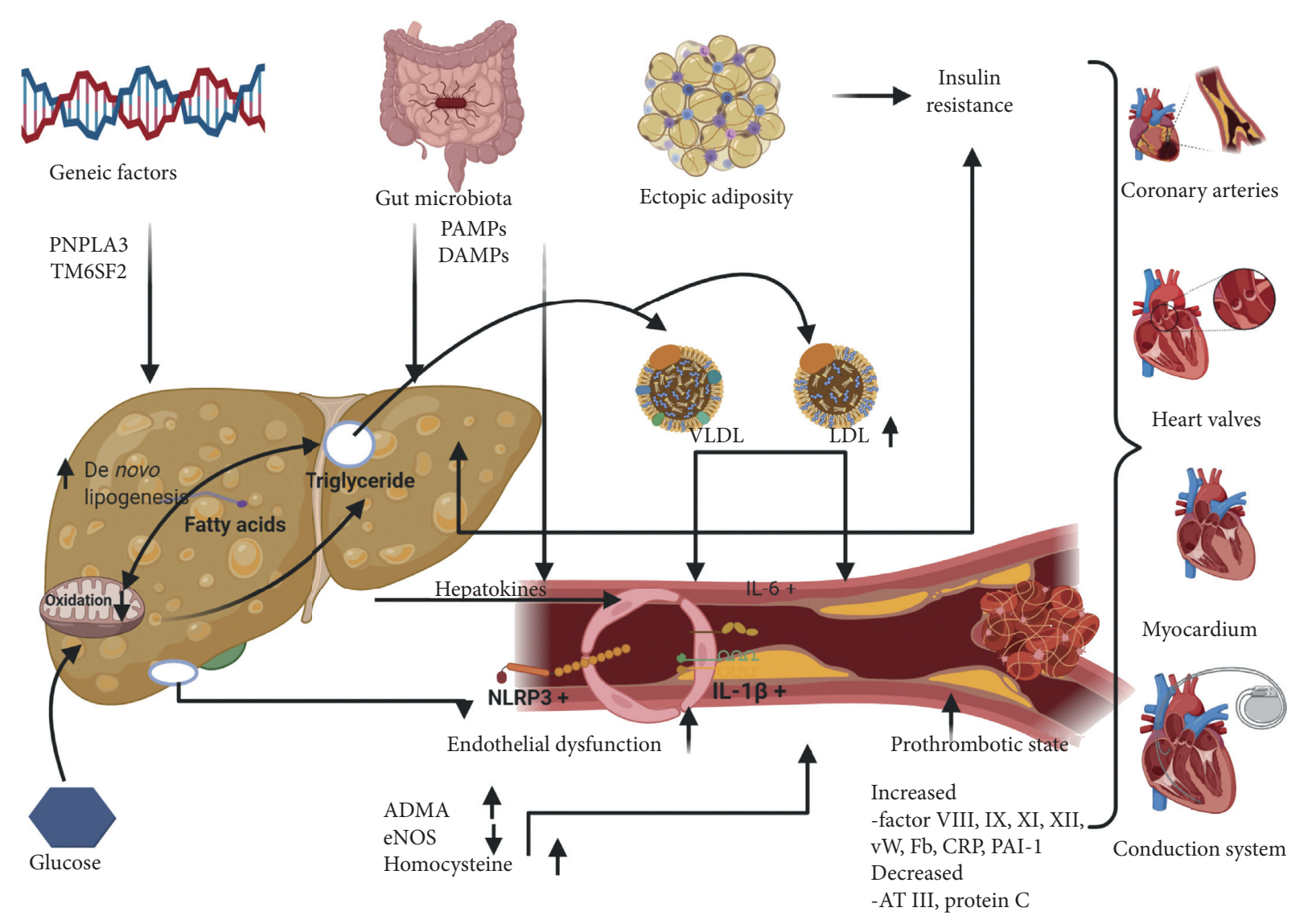

Coronary arteries
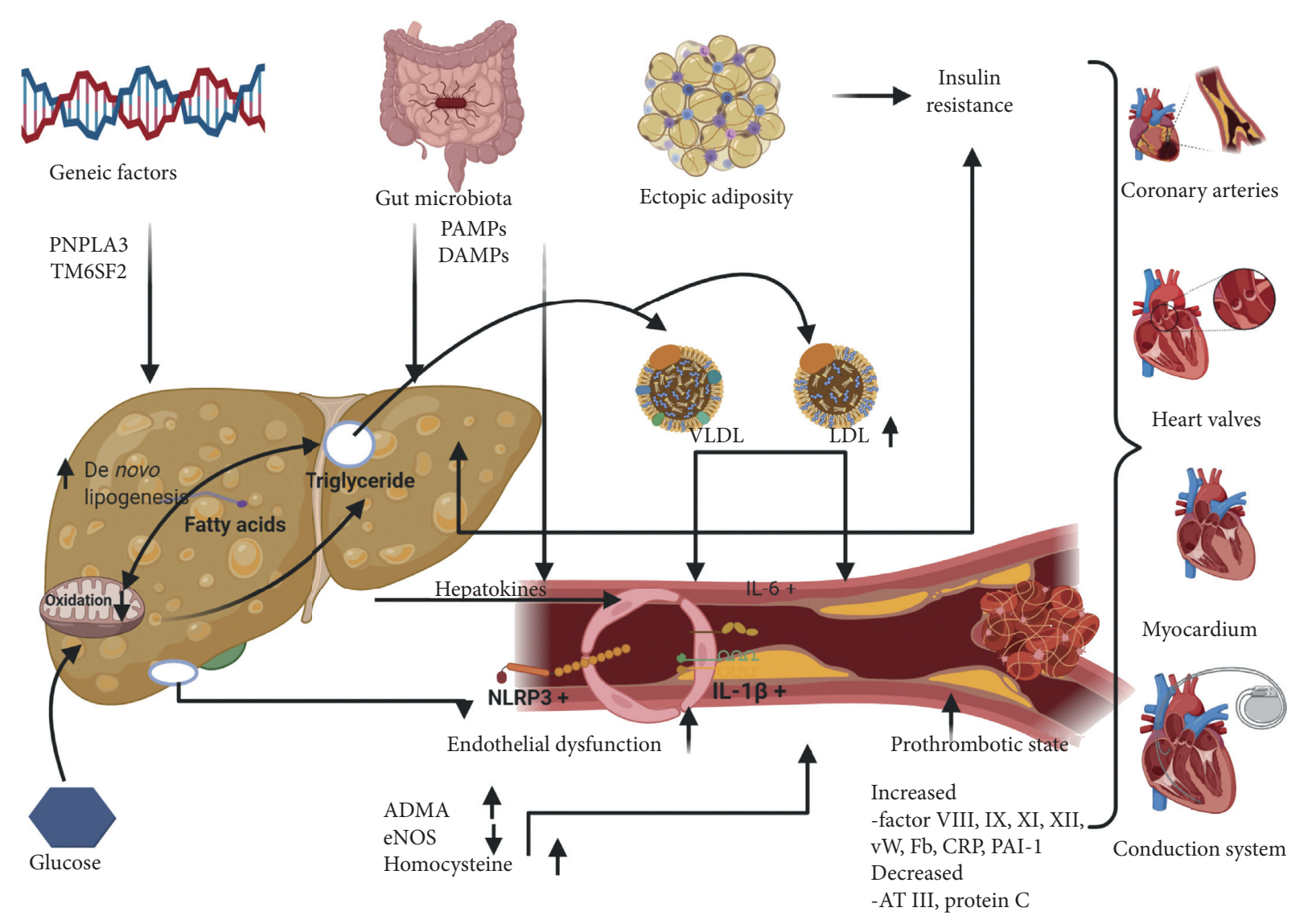

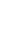

(1)

FIgURe 1: Pathophysiology of cardiovascular involvement in NAFLD.

inflammatory syndrome is changing the epicardial adipose tissue phenotype, transforming these cells in activated adipose cells that secret proinflammatory cytokines, activate profibrotic pathways, and promote ventricular fibrosis and inflammation [35-37].

The previous studies demonstrated that NAFLD has also a genetic predisposition. The polymorphism in the patatinlike phospholipase domain-containing 3 (PNPLA3) and the transmembrane 6 superfamily member 2 (TM6SF2) genes are associated with NAFLD, NASH, fibrosis, and an increased risk of hepatocellular carcinoma [38]. PNPLA3 I148 $\mathrm{M}$ and TM6SF2 E167 K are variants that interfere with hepatic triglyceride metabolism $[39,40]$. Both variants are predisposing the patients to NAFLD and are associated with increased disease severity [41]. Interestingly, carriers of genetic variants of PNPLA3 and TM6SF2 tend to have cardioprotective phenotype [42, 43], although the precise in vivo physiological role of PNPLA3 remains incompletely characterized.

Recently, gut microbiota was demonstrated as a contributing factor for atherosclerosis, T2DM, and NAFLD [44, 45]. The impaired gut mucosal barrier permits pathogen-associated molecular patterns (PAMPs) and damaged-associated molecular patterns (DAMPs) entering the systemic circulation, inducing a gut-related inflammatory response [46, 47]. NAFLD and advanced fibrosis are associated with an increased concentration of Escherichia coli bacteria, Ruminococcus, and Blautia and a decrease in Firmicutes strains [48-50]. This profound intestinal dysbiosis is independent of IR and obesity and is related to increased gut-derived metabolites as 3-(4hydroxyphenyl)-lactate or phenylacetate. Also, gut-derived microbiota and its metabolites were recently demonstrated as potentially important players in cardiovascular disease pathophysiology [51].

All this evidence supports the important role of the liver in the pathophysiologic processes of CVD development, although an independent link between NAFLD and coronary arterial disease and atherosclerosis remains difficult to confirm.

\section{Cardiovascular Risk Assessment in NAFLD}

NAFLD shares many risk factors with CVD, most notably insulin resistance, obesity, and dyslipidemia. Also, NAFLD itself likely influences CVD development, by means of hypertriglyceridemia and induction of a hypercoagulable state $[10,30,52]$.

Several studies demonstrated that all stages of NAFLD are associated with increased CVEs as acute coronary syndrome, stroke, or malignant arrhythmias. Moreover, compared with patients without NAFLD, those with fatty liver have an elevated risk of CVEs independent of the presence of MetS or T2DM [6,53]. Even in normoponderal patients, ultrasound-defined NAFLD is correlated with a high incidence of CVEs, concluding that NAFLD acts independently of overweight and obesity [54]. 
Recent data also suggested that patients with NAFLD had a twofold increase in the risk of developing CVEs, and in those with liver fibrosis this risk was doubled [6].

As a systemic progressive disease, NAFLD increases the risk of CVD, although the most commonly used cardiovascular risk factor scoring system for cardiovascular risk management, such as the Framingham Risk Score or SCORE, may underestimate cardiovascular risk in this special patient category. No validated CVD risk score specific for NAFLD patients has yet been validated.

The most important clinical practice issue is that NAFLD diagnosis could be associated with an additional risk for CVD when concomitant atherosclerotic risk factors are already diagnosed, although before including NAFLD in new cardiovascular risk scores we should establish a consensus on how to quantify and qualify NAFLD severity. Until then, the use of classical risk factors is adequate to evaluate CVD risk in NAFLD patients, as Treeprasertsuk et al.demonstrated. In this study, the Framingham Risk Score had a good sensibility in identifying coronary heart disease risk in a cohort with more than 300 NAFLD patients followed by a mean of 11.5 years [55].

An important clinical question is if NAFLD indicates the need for an extensive cardiovascular risk assessment independently of the presence of classical risk factors. Many cross-sectional studies confirmed the independent associations between NAFLD and the presence of subclinical vascular disease or changes in heart morphology such as left ventricular hypertrophy or diastolic dysfunction. However, there is no prospective evaluation showing an additional role of these imaging tests in CVD risk evaluation. Therefore, there is not enough evidence to routinely recommend imaging tests for subclinical vascular or heart disease based on the presence of NAFLD. The association between NAFLD and CVD is further described in Table 1.

\subsection{Impact of NAFLD on Cardiovascular Disease Outcome.} Several meta-analyses reported conflicting results regarding cardiovascular mortality rate in patients with NAFLD. A meta-analysis including 16 studies demonstrated an increased risk of CVEs in NAFLD patients compared to those without NAFLD [10]. However, the CVD-related mortality was higher only in patients with $\mathrm{NASH}$ and high fibrosis scores or high histological fibrosis stage. A second metaanalysis found an increased liver-related mortality in patients with NAFLD, with no correlation with CVD-related mortality [72]. Moreover, a meta-analysis of 34 studies including more than 160,000 patients by $\mathrm{Wu}$ et al. was unable to confirm a correlation between the presence of NAFLD and increased cardiovascular mortality [73]. The major limitation of these meta-analyses lies in the heterogeneity of diagnosis criteria of NASH. However, in consideration of all studies, the meta-analysis of $\mathrm{Wu}$ et al. confirmed that NAFLD was associated with an increased risk for incident CVD (HR 1.37; 95\% CI 1.10-1.72) and that NAFLD patients were more likely to develop coronary heart disease (HR 2.31; 95\% CI 1.46-3.65) and hypertension (HR 1.16; 95\% CI 1.06-1.27) [73]. In addition, it was demonstrated that the severity of NAFLD was a major determinant of increased risk of CVD [74]. A comprehensive meta-analysis performed by Younossi et al.that included 86 studies, with a sample size of $8,515,431$ patients, reported a pooled CVD-related mortality rate in patients with NAFLD of 4.8 per 1000 person-years [75].

Current evidence shows that NAFLD is associated with an increased risk for CVD and CVEs. Patients with NASH and advanced fibrosis as well as NAFLD patients with concomitant T2DM can be identified as being part of a special risk group [76-78].

Ekstedt et al., in a study with a mean follow-up duration of 26.4 years, stated that patients with NAFLD presented higher mortality than patients from the general population (HR: 1.29; 95\% CI 1.04-1.59) [43]. The authors identified CVD as well as liver-related disease to be the main causes of death in patients with NAFLD. Patients with more advanced fibrosis stage presented increased mortality (HR 3.3, CI 2.27-4.76, $P<0.001$ ) [8]. A prospective study including 898 patients that were screened for steatosis by ultrasound found that CVEs, defined as ischemic stroke, myocardial infarction, revascularization procedures, newly diagnosed arterial fibrillation, and cardiovascular death, were associated with NAFLD. The authors also concluded that the presence of NAFLD determined a 2-fold increase in the risk of CVEs. The patients with liver fibrosis presented a higher, $4 \mathrm{x}$ increase in the risk for development of CVEs. Kim et al., in a large study comprising 11,154 patients among whom 34\% were diagnosed with NAFLD, reported that fibrosis but not NAFLD was associated with increased mortality. CVD represented the main cause of death [79]. A more recent meta-analysis that included 108,711 patients with NAFLD, $44 \%$ women and $56 \%$ men, showed that CVEs and mortality were twice higher in women than in men (OR 2.12, 95\% CI 1.65-2.73, $P<0.001$ ) [80].

While simple steatosis alone confers less cardiovascular risk than $\mathrm{NASH}$, the individual overall cardiovascular risk results from the combination of NAFLD stage and cardiometabolic risk factors.

\section{Cardiovascular Comorbidities in NAFLD}

4.1. NAFLD and Atherosclerosis. Atherosclerosis is defined by the development of neointimal cholesterotic plaques in large arteries and is directly associated with acute coronary syndrome and stroke.

Several studies have demonstrated that NAFLD is a risk factor for atherosclerosis and, therefore, associated with increased prevalence of ischemic heart disease [81-85]. Atherosclerosis has been extensively documented in patients with NAFLD and subclinical markers of atherosclerosis such as coronary artery calcium (CAC) score [86, 87], as well as carotid intima-media thickness (cIMT) [88-90] or arterial stiffness via brachial-ankle index, have been used to confirm this association. Prospective studies have demonstrated that NAFLD patients are associated with higher CAC scores than those without NAFLD [91, 92], even among patients with normal body mass index (BMI). The annual rate of CAC progression and the cIMT were higher in NAFLD patients 
TABLE 1: Current evidence of the association between NAFLD and CVD.

\begin{tabular}{|c|c|c|c|c|c|}
\hline Authors, year & Country & Type of study & Main characteristics & $\begin{array}{l}\text { NAFLD } \\
\text { diagnostic }\end{array}$ & Results \\
\hline $\begin{array}{l}\text { Bonnet et al., } \\
2017 \text { [56] }\end{array}$ & France & $\begin{array}{c}\text { Prospective, } \\
\text { cohort }\end{array}$ & $\begin{array}{l}2,565 \text { patients, } \\
\text { normotensive, followed } \\
\text { up for } 9 \text { years }\end{array}$ & GGT, FLI & $\begin{array}{l}\text { GGT was associated with incident } \\
\text { hypertension (standardized odds } \\
\text { ratio: } 1.21 ; 95 \% \text { confidence interval } \\
(1.10-1.34) ; P=0.0001 \text { ). FLI predicted } \\
\text { incident hypertension in a } \\
\text { multivariable model. }\end{array}$ \\
\hline $\begin{array}{l}\text { Huh et al., } \\
2015 \text { [57] }\end{array}$ & South Korea & $\begin{array}{l}\text { Prospective, } \\
\text { cohort }\end{array}$ & $\begin{array}{c}\text { 1,521 patients, aged } \\
40-70, \text { followed up for } 2.6 \\
\text { years }\end{array}$ & FLI & $\begin{array}{l}10.06 \% \text { of patients developed } \\
\text { hypertension; FLI was associated with } \\
\text { baseline blood pressure and was an } \\
\text { independent risk factor for } \\
\text { hypertension. }\end{array}$ \\
\hline $\begin{array}{l}\text { Lau et al., } \\
2010[58]\end{array}$ & Germany & $\begin{array}{l}\text { Prospective, } \\
\text { cohort }\end{array}$ & $\begin{array}{l}3191 \text { patients, aged } 20-79 \\
\text { followed up for } 11.6 \text { years }\end{array}$ & $\begin{array}{l}\text { US and liver } \\
\text { Enzymes }\end{array}$ & $\begin{array}{l}\text { Fatty liver disease was associated with } \\
\text { hypertension at baseline and at follow- } \\
\text { up, OR } 2.8 \text {; } 95 \% \text { CI } 1.3-6.2 \text { and OR } \\
\text { 3.1; } 95 \% \text { CI } 1.7-5.8 \text {, respectively. }\end{array}$ \\
\hline $\begin{array}{l}\text { Ryoo et al., } \\
2014 \text { [59] }\end{array}$ & South Korea & $\begin{array}{l}\text { Prospective, } \\
\text { cohort }\end{array}$ & $\begin{array}{c}11350 \text { patients, only men, } \\
\text { aged } 30-59 \text {, } \\
\text { normotensive, followed } \\
\text { up for } 5 \text { years }\end{array}$ & US & $\begin{array}{l}58.2 \% \text { of the participants developed } \\
\text { prehypertension, } 63.7 \% \text { of the patients } \\
\text { with mild NAFLD, and } 70.3 \% \text { of the } \\
\text { ones with severe NAFLD, } P<0.001 \text {. }\end{array}$ \\
\hline $\begin{array}{l}\text { Sung et al., } \\
2014,[60]\end{array}$ & South Korea & $\begin{array}{l}\text { Retrospective, } \\
\text { cohort }\end{array}$ & $\begin{array}{l}11448 \text { patients, aged } \\
42.1 \pm 6.8, \text { normotensive, } \\
\text { followed up for } 5 \text { years }\end{array}$ & US & $\begin{array}{l}\text { NAFLD was associated with incident } \\
\text { hypertension, after adjustment for } \\
\text { multiple confounders }[\mathrm{aOR}=1.60 \\
(95 \% \text { CI } 1.30,1.96 ; P<0.001)] .\end{array}$ \\
\hline $\begin{array}{l}\text { Agac et al., } \\
2013[61]\end{array}$ & Turkey & $\begin{array}{l}\text { Prospective, } \\
\text { cross-sectional }\end{array}$ & $\begin{array}{l}80 \text { patients with acute } \\
\text { coronary syndrome }\end{array}$ & US & $\begin{array}{l}\text { NAFLD was present in } 81.2 \% \text { of the } \\
\text { patients with acute coronary } \\
\text { syndrome; multivariate analysis found } \\
\text { NAFLD to be associated with higher } \\
\text { SYNTAX score (OR, } 13.20 \text {; } 95 \% \text { CI, } \\
\text { 2.52-69.15). }\end{array}$ \\
\hline $\begin{array}{l}\text { Agarwal } \\
\text { et al., } 2011 \\
{[62]}\end{array}$ & India & $\begin{array}{l}\text { Prospective, } \\
\text { cross-sectional }\end{array}$ & 124 patients with T2DM & US & $\begin{array}{l}\text { CAD was diagnosed in } 60.5 \% \text { of the } \\
\text { patients with NAFLD and in } 45.2 \% \text { of } \\
\text { the ones without NAFLD. }\end{array}$ \\
\hline $\begin{array}{l}\text { Arslan et al., } \\
2012[63]\end{array}$ & Turkey & $\begin{array}{l}\text { Prospective, } \\
\text { cross-sectional }\end{array}$ & $\begin{array}{c}151 \text { patients with newly } \\
\text { diagnosed CAD, without } \\
\text { T2DM }\end{array}$ & US & $\begin{array}{l}\text { NAFLD was diagnosed in } 64.9 \% \text { of the } \\
\text { patients. Presence of NAFLD was } \\
\text { associated with poor coronary } \\
\text { collateral development. }\end{array}$ \\
\hline $\begin{array}{l}\text { Chan et al., } \\
2014 \text { [64] }\end{array}$ & Malaysia & $\begin{array}{l}\text { Prospective, } \\
\text { cross-sectional }\end{array}$ & $\begin{array}{l}399 \text { diabetic patients, } \\
\text { mean age } 62.8 \pm 10.5\end{array}$ & US & $\begin{array}{c}\text { NAFLD was found in } 49.6 \% \text { of } \\
\text { patients but was not associated with } \\
\text { IHD. }\end{array}$ \\
\hline $\begin{array}{l}\text { Chen et al., } \\
2010 \text { [65] }\end{array}$ & Taiwan, China & $\begin{array}{l}\text { Retrospective, } \\
\text { cross-sectional }\end{array}$ & 295 patients & US, CT & $\begin{array}{l}\text { NAFLD (OR, 2.462; } 95 \% \text { CI, } \\
1.065-5.691) \text { was found to be an } \\
\text { independent factor for the risk of } \\
\text { coronary artery calcifications. }\end{array}$ \\
\hline $\begin{array}{l}\text { Chiang et al., } \\
2010 \text { [66] }\end{array}$ & Taiwan, China & $\begin{array}{l}\text { Retrospective, } \\
\text { cross-sectional }\end{array}$ & 724 patients & US & $\begin{array}{l}\text { NAFLD was found to be an } \\
\text { independent predictor for future CVD } \\
\text { risk } \geq 10 \% \text { (OR: } 1.89, P=0.004) \text {. }\end{array}$ \\
\hline $\begin{array}{l}\text { Keskin et al., } \\
2017 \text { [67] }\end{array}$ & Turkey & $\begin{array}{l}\text { Retrospective, } \\
\text { cohort }\end{array}$ & 360 patients with STEMI & US & $\begin{array}{l}\text { Multivariate analysis found grade } 3 \\
\text { NAFLD to be a risk factor for in- } \\
\text { hospital mortality (OR } 4.2 \text { ) }\end{array}$ \\
\hline $\begin{array}{l}\text { Perera et al., } \\
2016[68]\end{array}$ & Sri Lanka & Prospective & $\begin{array}{l}120 \text { patients with acute } \\
\text { coronary syndrome }\end{array}$ & US & $\begin{array}{l}\text { NAFLD was identified in } 46.7 \% \text { of the } \\
\text { participants. NAFLD was associated } \\
\text { with a higher predicted in-hospital } \\
\text { mortality (adjusted OR } 31.3 \text {, CI } \\
2.2-439.8, P=0.011 \text { ) and at } 6 \text { months } \\
\text { after discharge (adjusted OR } 15.59 \text {, CI } \\
\text { 1.6-130.6, } P=0.011 \text { ). }\end{array}$ \\
\hline
\end{tabular}


TABle 1: Continued.

\begin{tabular}{|c|c|c|c|c|c|}
\hline Authors, year & Country & Type of study & Main characteristics & $\begin{array}{c}\text { NAFLD } \\
\text { diagnostic }\end{array}$ & Results \\
\hline $\begin{array}{l}\text { Wu et al., } \\
2017 \text { [69] }\end{array}$ & China & Cross-sectional & 2345 patients & US & $\begin{array}{l}\text { NAFLD was significantly associated } \\
\text { with the development of coronary } \\
\text { artery calcifications (adjusted OR: } \\
1.348,95 \% \text { CI: } 1.030-1.765 \text { ). }\end{array}$ \\
\hline $\begin{array}{l}\text { Baratta et al., } \\
2020[6]\end{array}$ & Italy & Prospective & $\begin{array}{l}898 \text { patients, followed up } \\
\text { for } 41.4 \text { months }\end{array}$ & US & $\begin{array}{c}\text { Patients with NAFLD presented over } \\
\text { 2x increase in risk of CVEs; patients } \\
\text { with liver fibrosis had a } 4 \mathrm{x} \text { increase in } \\
\text { risk. }\end{array}$ \\
\hline $\begin{array}{l}\text { Pastori et al., } \\
2020[70]\end{array}$ & Multicenter & $\begin{array}{l}\text { Prospective, } \\
\text { cohort }\end{array}$ & $\begin{array}{l}1735 \text { patients with } \\
\text { nonvalvular atrial } \\
\text { fibrillation }\end{array}$ & FLI & $\begin{array}{l}\text { NAFLD was diagnosed in } 42.2 \% \text { of the } \\
\text { participants but was not associated } \\
\text { with bleeding or with thrombotic risk. }\end{array}$ \\
\hline $\begin{array}{l}\text { Alexander } \\
\text { et al., } 2019 \\
\text { [71] }\end{array}$ & $\begin{array}{l}\text { Multicenter (Italy, } \\
\text { Netherlands, Spain, } \\
\text { United Kingdom) }\end{array}$ & $\begin{array}{l}\text { Matched cohort } \\
\text { study }\end{array}$ & $\begin{array}{l}120795 \text { patients with } \\
\text { NAFLD or NASH }\end{array}$ & l & $\begin{array}{l}\text { NAFLD was not found to be } \\
\text { associated with increased risk for } \\
\text { acute myocardial infarction. }\end{array}$ \\
\hline
\end{tabular}

NAFLD: nonalcoholic fatty liver disease; FLI: fatty liver index; US: ultrasound; OR: odds ratio; CI: confidence interval; HR: hazard ratio; CAD: coronary artery disease; T2DM: type 2 diabetes mellitus; CAD: coronary artery disease; IHD: ischemic heart disease; CT: computed tomography; CVD: cardiovascular disease; STEMI: ST segment elevation myocardial infarction; CVE: cardiovascular event; NASH: nonalcoholic steatohepatitis.

independent of obesity, dyslipidemia, or T2DM $[86,93,94]$. Also, increased cIMT was associated with the presence of liver fibrosis assessed by fibrosis-4 (FIB4) and aspartate transaminase to platelet ratio index (APRI) scores [95]. NAFLD is associated with plaques development not only in coronary arteries but also in carotid arteries, iliac arteries, or celiac trunk [96], with predisposition to multiarterial calcifications.

Moreover, NAFLD has also been associated with endothelial dysfunction [97] as well as with unstable coronary plaques [98] explaining the high risk of ischemic events in these patients [3]. Furthermore, patients with ST segment elevation myocardial infarction (STEMI) presented higher short-term mortality and worse long-term prognostic when NAFLD was associated [67].

A meta-analysis including more than 85,000 patients demonstrated that subclinical atherosclerosis was significantly more frequent in those patients diagnosed with NAFLD (OR $=1.60$, 95\% CI: $1.45-1.78)$ [89].

NAFLD increases the atherosclerotic risk and makes the patients prone to the development of unstable plaques adding to cardiovascular risk factors as dyslipidemia, obesity, arterial hypertension, and T2DM.

4.2. NAFLD and the Cardiac Structure. NAFLD has been associated with structural heart disease. Diastolic dysfunction and heart failure with a preserved ejection fraction and increased myocardial remodeling are common findings in patients with NAFLD [35]. These changes, together with an increased risk of aortic sclerosis [99], can lead to the development of arrhythmias and the increased risk for CVD events [100].

4.3. NAFLD and Arrhythmias. NAFLD has been associated with increased risk of atrial fibrillation [101] and prolonged QTc interval [102]. The physiopathological mechanisms that lead to arrhythmias in patients with NAFLD include the increase of the epicardial adiposity which associates a rise in proinflammatory adipocytokines, followed by the development of myocardial fibrosis [35]. Targher et al., in a prospective study including diabetic patients, reported a high risk for atrial fibrillation when NAFLD was associated, with an OR of 4.49 for a 95\% CI between 1.6 and 12.9 [101]. Another prospective study comprising patients followed up for 16.3 years reported an independent association between NAFLD and atrial fibrillation, with an adjusted OR of 1.88 for a 95\% CI between 1.03 and 3.45 [103]. Ventricular arrhythmias were also associated with NAFLD, in a retrospective study on patients with type 2 diabetes that underwent 24-hour Holter monitoring. After adjusting for confounders, the authors reported an OR of 3.01 for a $95 \%$ CI between 1.26 and 7.17 [104].

4.4. NAFLD and Hypertension. The relation between NAFLD and hypertension has not yet been fully explained. There are indications that the systemic inflammation associated with NAFLD could promote the activation of the sympathetic nervous system and, thus, induce hypertension [105]. Moreover, insulin resistance would promote hypertension via the augmentation of free fatty acids that lead to perivascular fat deposits situated in the vicinity of vessels and the renal sinus. Furthermore, the high levels of homocysteine found in the setting of NAFLD can, together with gut dysbiosis, induce the increase in oxidative stress and thus promote hypertension [106]. Although several studies demonstrated an association between NAFLD and hypertension [57-59, 107], there was considerable heterogeneity concerning the criteria used for the diagnosis of NAFLD.

While some studies used ultrasonography for the diagnosis of NAFLD [58,59], others used magnetic resonance imaging (MRI) [108] or surrogate scores such as fatty liver index (FLI) [57]. Lau et al., in a prospective study including 3191 patients from Germany, concluded that the subjects diagnosed with NAFLD presented a higher risk of hypertension than patients without NAFLD, reporting an OR of 
3.1 for a $95 \%$ CI of 1.7-5.8 [58]. Another larger prospective study from South Korea, including 11,350 male patients, found a higher risk for prehypertension in patients with NAFLD. Interestingly, the risk varied according to NAFLD severity [59]. Huh et al. evaluated the risk for hypertension in a prospective longitudinal study including 1,521 patients without CVD. The authors found that the risk for hypertension was higher in the NAFLD group as diagnosed by FLI and that the risk increased gradually in accordance with the FLI value [57]. More recently, Lorbeer et al., in a study that used MRI in order to measure the hepatic fat fraction, reported an association of the liver fat content with high blood pressure as well as with higher odds of hypertension [107].

4.5. CVD Events and Associated Mortality in Patients with NAFLD. Numerous studies and meta-analysis have found CVD events to be associated with NAFLD and CVD-related death has been considered the main cause of mortality in these patients $[8,108]$. The risk of death following a CVD event in patients with NAFLD was also analyzed in a recent meta-analysis including 16 studies with a total of 34,043 patients. The pooled results indicated an increased risk for fatal and nonfatal CVD events in patients with NAFLD, with an OR of $1.64,95 \%$ CI $1.26-2.13$, but the direct causality between NAFLD and CVD events could not be demonstrated because of the observational design of the studies included [100]. A recent study performed by Paik et al. using mortality data from the National Vital Statistics System multiple-cause mortality data between 2007 and 2016 identified 353,234 patients diagnosed with NAFLD. The authors concluded that CVD was the second most frequent cause of death in these patients, following liver cirrhosis [109].

A recent large retrospective study carried out in Germany and involving 111,492 patients showed an increased risk of myocardial infarction when NAFLD was associated, with a hazard ratio of 2.14 (95\% CI 1.59, 2.89) [110]. A comprehensive analysis of 285 patients with biopsy-proven NAFLD monitored for 5.2 years showed that advanced fibrosis was a predictor of CVD events and that the NAFLD fibrosis score was the only noninvasive predictor of CVD [111]. However, there is still some controversy regarding the risk of ischemic events in the setting of NAFLD. A matched cohort study of 18 million Europeans including patients from electronic primary healthcare databases from Italy, Netherlands, Spain, and the United Kingdom did not find an increased risk of myocardial infarction or of stroke in patients with NAFLD [71]. However, the design of the study presented the risk for misclassification of the disease; thus, the results should be interpreted with caution.

\section{Unmet Needs}

Long-term assessment of a larger number of histologically diagnosed patients is needed to understand the causes of mortality in NASH and the direct relation with CVD-related events and mortality. Further studies should focus on the role of NAFLD-associated inflammation as a new cardiovascular risk. Also, future studies should be aimed at unraveling the role of other NAFLD-mediated pathways, such as hepatic inflammation, in the pathogenesis of atherosclerosis.

In addition, it is important to better clarify how NAFLD progression from steatosis to more severe disease influences the metabolic and inflammatory components that may associate this disease with atherosclerosis. Prospective long-term studies with homogeneous diagnostic criteria, considering not only the presence but also the severity of NALFD, are necessary to test if this diagnosis can improve cardiovascular disease risk stratification. The greatest challenge would be to separate it from its aggravating metabolic consequences that characterize the MetS, like atherogenic dyslipidemia.

In the meantime, considering the associated higher cardiovascular risk, weight loss, exercise, and control of concomitant established risk factors for atherosclerosis are mandatory in individuals with NAFLD.

\section{Conclusions}

The causal relationship between CVD and NAFLD remains under investigation, but the strong bidirectional association between CVD and NAFLD warrants clinical intervention in patients with NAFLD to modify metabolic risk factors, including T2DM, dyslipidemia, hypertension, and obesity.

Although current cardiovascular society guidelines have not identified NAFLD as an independent risk factor for CVD despite recent studies suggesting NAFLD's role in incident CVD, vigilant age-appropriate screening and treatment for associated risk factors, including weight loss for obesity, glycemic control for T2DM, and treatment of hypertension and hyperlipidemia, remain prudent strategies that should be supported by clinicians managing patients with NAFLD.

Cardiologists should be aware that patients with CVD may have progressive forms of NAFLD, while hepatologists should be aware that patients with progressive NAFLD have a markedly increased risk of CVD. All physicians should perform correct cardiovascular risk management, in a multidisciplinary setting, all these in the best interest of the patients.

\section{Abbreviations}

ADMA: Asymmetric dimethyl arginine

ATIII: Antithrombin III

CRP: C-reactive protein

DAMPs: Damaged-associated molecular patterns

Fb: $\quad$ Fibrinogen

IL-6: $\quad$ Interleukin 6

IL-1 $\beta$ : Interleukin $1 \beta$

LDL: $\quad$ Low-density lipoprotein

NLRP3: Pyrin domain-containing protein 3

PAI-1: Plasminogen activator inhibitor-1

PAMPs: Pathogen-associated molecular patterns

PNPLA3: Patatin-like phospholipase domain-containing 3

TM6SF2: Transmembrane 6 superfamily member 2

VLDL: Very low-density lipoprotein

vW: Von Willebrand factor. 


\section{Data Availability}

The data used to support this study are included within this article.

\section{Conflicts of Interest}

The authors declare that they have no conflicts of interest.

\section{Authors' Contributions}

All authors contributed equally to this review. All authors have read and agreed on the published version of the manuscript.

\section{References}

[1] Z. M. Younossi, "Non-alcoholic fatty liver disease - a global public health perspective," Journal of Hepatology, vol. 70, no. 3, pp. 531-544, 2019.

[2] B. J. Perumpail, M. A. Khan, E. R. Yoo, G. Cholankeril, D. Kim, and A. Ahmed, "Clinical epidemiology and disease burden of nonalcoholic fatty liver disease," World Journal of Gastroenterology, vol. 23, no. 47, pp. 8263-8276, 2017.

[3] P. Kasper, A. Martin, S. Lang et al., "NAFLD and cardiovascular diseases: a clinical review," Clinical Research in Cardiology, 2020.

[4] L. Calzadilla Bertot and L. Adams, "The natural course of non-alcoholic fatty liver disease," International Journal of Molecular Sciences, vol. 17, no. 5, p. 774, 2016.

[5] R. Loomba and L. A. Adams, "The $20 \%$ rule of NASH progression: the natural history of advanced fibrosis and cirrhosis caused by NASH," Hepatology, vol. 70, no. 6, pp. 1885-1888, 2019.

[6] F. Baratta, D. Pastori, F. Angelico et al., "Nonalcoholic fatty liver disease and fibrosis associated with increased risk of cardiovascular events in a prospective study," Clinical Gastroenterology and Hepatology, vol. 18, no. 10, pp. 23242331, 2020.

[7] M. Ekstedt, L. E. Franzén, U. L. Mathiesen et al., "Long-term follow-up of patients with NAFLD and elevated liver enzymes," Hepatology, vol. 44, no. 4, pp. 865-873, 2006.

[8] M. Ekstedt, H. Hagström, P. Nasr et al., "Fibrosis stage is the strongest predictor for disease-specific mortality in NAFLD after up to 33 years of follow-up," Hepatology, vol. 61, no. 5, pp. 1547-1554, 2015.

[9] M. C. G. J. Brouwers, N. Simons, C. D. A. Stehouwer, and A. Isaacs, "Non-alcoholic fatty liver disease and cardiovascular disease: assessing the evidence for causality," Diabetologia, vol. 63, no. 2, pp. 253-260, 2020.

[10] G. Targher, C. D. Byrne, A. Lonardo, G. Zoppini, and C. Barbui, "Non-alcoholic fatty liver disease and risk of incident cardiovascular disease: a meta-analysis," Journal of Hepatology, vol. 65, no. 3, pp. 589-600, 2016.

[11] K. M. Korenblat, E. Fabbrini, B. S. Mohammed, and S. Klein, "Liver, muscle, and adipose tissue insulin action is directly related to intrahepatic triglyceride content in obese subjects," Gastroenterology, vol. 134, no. 5, pp. 1369-1375, 2008.

[12] E. P. Stahl, D. S. Dhindsa, S. K. Lee, P. B. Sandesara, N. P. Chalasani, and L. S. Sperling, "Nonalcoholic fatty liver disease and the heart," Journal of the American College of Cardiology, vol. 73, no. 8, pp. 948-963, 2019.

[13] K. Cusi, "Role of obesity and lipotoxicity in the development of nonalcoholic steatohepatitis: pathophysiology and clinical implications," Gastroenterology, vol. 142, no. 4, pp. 711-725, 2012.

[14] K. Lechner, A. L. McKenzie, N. Kränkel et al., "High-risk atherosclerosis and metabolic phenotype: the roles of ectopic adiposity, atherogenic dyslipidemia, and inflammation," Metabolic Syndrome and Related Disorders, vol. 18, no. 4, pp. 176-185, 2020.

[15] G. I. Shulman, "Ectopic fat in insulin resistance, dyslipidemia, and cardiometabolic disease," New England Journal of Medicine, vol. 371, no. 12, pp. 1131-1141, 2014.

[16] M. C. Petersen and G. I. Shulman, "Mechanisms of insulin action and insulin resistance," Physiological Reviews, vol. 98, no. 4, pp. 2133-2223, 2018.

[17] C. C. Low Wang, C. N. Hess, W. R. Hiatt, and A. B. Goldfine, "Clinical update: cardiovascular disease in diabetes mellitus," Circulation, vol. 133, no. 24, pp. 2459-2502, 2016.

[18] M. G. White, J. A. M. Shaw, and R. Taylor, "Type 2 diabetes: the pathologic basis of reversible $\beta$-cell dysfunction," Diabetes Care, vol. 39, no. 11, pp. 2080-2088, 2016.

[19] D. Kim, G. E. Chung, M.-S. Kwak et al., "Body fat distribution and risk of incident and regressed nonalcoholic fatty liver disease," Clinical Gastroenterology and Hepatology, vol. 14, no. 1, pp. 132-138, 2016.

[20] F. Benhamed, P.-D. Denechaud, M. Lemoine et al., "The lipogenic transcription factor ChREBP dissociates hepatic steatosis from insulin resistance in mice and humans," Journal of Clinical Investigation, vol. 122, no. 6, pp. 21762194, 2012.

[21] J. Borén, M. J. Chapman, R. M. Krauss et al., "Low-density lipoproteins cause atherosclerotic cardiovascular disease: pathophysiological, genetic, and therapeutic insights: a consensus statement from the European Atherosclerosis Society Consensus Panel," European Heart Journal, vol. 41, no. 24, pp. 2313-2330, 2020.

[22] S. Goulopoulou, C. G. McCarthy, and R. C. Webb, "Toll-like receptors in the vascular system: sensing the dangers within," Pharmacological Reviews, vol. 68, no. 1, pp. 142-167, 2016.

[23] S. Zewinger, J. Reiser, V. Jankowski et al., "Apolipoprotein C3 induces inflammation and organ damage by alternative inflammasome activation," Nature Immunology, vol. 21, no. 1 , pp. $30-41,2020$.

[24] P. Libby and B. M. Everett, "Novel antiatherosclerotic therapies," Arteriosclerosis, Thrombosis, and Vascular Biology, vol. 39, no. 4, pp. 538-545, 2019.

[25] D. H. Hwang, J.-A. Kim, and J. Y. Lee, "Mechanisms for the activation of Toll-like receptor $2 / 4$ by saturated fatty acids and inhibition by docosahexaenoic acid," European Journal of Pharmacology, vol. 785, pp. 24-35, 2016.

[26] S. M. Francque, D. van der Graaff, and W. J. Kwanten, "Nonalcoholic fatty liver disease and cardiovascular risk: pathophysiological mechanisms and implications," Journal of Hepatology, vol. 65, no. 2, pp. 425-443, 2016.

[27] G. H. Scholz and M. Hanefeld, "Metabolic vascular syndrome: new insights into a multidimensional network of risk factors and diseases," Visceral Medicine, vol. 32, no. 5, pp. 319-326, 2016.

[28] S. C. R. de Carvalho, M. T. C. Muniz, M. D. V. Siqueira et al., "Plasmatic higher levels of homocysteine in Non-alcoholic fatty liver disease (NAFLD)," Nutrition Journal, vol. 12, no. 1, 2013.

[29] A. Pastore, A. Alisi, G. di Giovamberardino et al., "Plasma levels of homocysteine and cysteine increased in pediatric NAFLD and strongly correlated with severity of liver 
damage," International Journal of Molecular Sciences, vol. 15, no. 11, pp. 21202-21214, 2014.

[30] A. Tripodi, A. L. Fracanzani, M. Primignani et al., "Procoagulant imbalance in patients with non-alcoholic fatty liver disease," Journal of Hepatology, vol. 61, no. 1, pp. 148-154, 2014.

[31] R. C. R. Meex and M. J. Watt, "Hepatokines: linking nonalcoholic fatty liver disease and insulin resistance," Nature Reviews Endocrinology, vol. 13, no. 9, pp. 509-520, 2017.

[32] N. Stefan and H.-U. Häring, "The role of hepatokines in metabolism," Nature Reviews Endocrinology, vol. 9, no. 3, pp. 144-152, 2013.

[33] D. Pal, S. Dasgupta, R. Kundu et al., "Fetuin-A acts as an endogenous ligand of TLR4 to promote lipid-induced insulin resistance," Nature Medicine, vol. 18, no. 8, pp. 1279-1285, 2012.

[34] J.-P. Després, "Body fat distribution and risk of cardiovascular disease," Circulation, vol. 126, no. 10, pp. 1301-1313, 2012.

[35] M. Packer, "Epicardial adipose tissue may mediate deleterious effects of obesity and inflammation on the myocardium," Journal of the American College of Cardiology, vol. 71, no. 20, pp. 2360-2372, 2018.

[36] G. Tsaban, A. Wolak, H. Avni-Hassid et al., "Dynamics of intrapericardial and extrapericardial fat tissues during longterm, dietary-induced, moderate weight loss," The American Journal of Clinical Nutrition, vol. 106, no. 4, pp. 984-995, 2017.

[37] O. Gruzdeva, E. Uchasova, Y. Dyleva et al., “Adipocytes directly affect coronary artery disease pathogenesis via induction of adipokine and cytokine imbalances," Frontier Immunology, vol. 10, 2019.

[38] L. A. Adams, Q. M. Anstee, H. Tilg, and G. Targher, "Nonalcoholic fatty liver disease and its relationship with cardiovascular disease and other extrahepatic diseases," Gut, vol. 66, no. 6, pp. 1138-1153, 2017.

[39] E. Trépo, S. Romeo, J. Zucman-Rossi, and P. Nahon, "PNPLA3 gene in liver diseases," Journal of Hepatology, vol. 65, no. 2, pp. 399-412, 2016.

[40] J. Kozlitina, E. Smagris, S. Stender et al., "Exome-wide association study identifies a TM6SF2 variant that confers susceptibility to nonalcoholic fatty liver disease," Nature Genetics, vol. 46, no. 4, pp. 352-356, 2014.

[41] Q. M. Anstee and C. P. Day, "The genetics of nonalcoholic fatty liver disease: spotlight on PNPLA3 and TM6SF2," Seminars in Liver Disease, vol. 35, no. 3, pp. 270-290, 2015.

[42] P. Dongiovanni, S. Petta, C. Maglio et al., "Transmembrane 6 superfamily member 2 gene variant disentangles nonalcoholic steatohepatitis from cardiovascular disease," Hepatology, vol. 61, no. 2, pp. 506-514, 2015.

[43] B. K. Lauridsen, S. Stender, T. S. Kristensen et al., "Liver fat content, non-alcoholic fatty liver disease, and ischaemic heart disease: mendelian randomization and meta-analysis of 279013 individuals," European Heart Journal, vol. 39, no. 5, pp. 385-393, 2018.

[44] J. Aron-Wisnewsky, C. Vigliotti, J. Witjes et al., "Gut microbiota and human NAFLD: disentangling microbial signatures from metabolic disorders," Nature Reviews Gastroenterology \& Hepatology, vol. 17, no. 5, pp. 279-297, 2020.

[45] M. Demir, S. Lang, A. Martin et al., "Phenotyping non-alcoholic fatty liver disease by the gut microbiota: ready for prime time?" Journal of Gastroenterology and Hepatology, vol. 35, no. 11, pp. 1969-1977, 2020.
[46] J. Ma and H. Li, "The role of gut microbiota in atherosclerosis and hypertension," Frontier Pharmacology, vol. 9, 2018.

[47] W. H. W. Tang, F. Bäckhed, U. Landmesser, and S. L. Hazen, "Intestinal microbiota in cardiovascular health and disease," Journal of the American College of Cardiology, vol. 73, no. 16, pp. 2089-2105, 2019.

[48] C. Caussy, A. Tripathi, G. Humphrey et al., "A gut microbiome signature for cirrhosis due to nonalcoholic fatty liver disease," Nature Communications, vol. 10, no. 1, 2019.

[49] F. Del Chierico, V. Nobili, P. Vernocchi et al., "Gut microbiota profiling of pediatric nonalcoholic fatty liver disease and obese patients unveiled by an integrated metaomics-based approach," Hepatology, vol. 65, no. 2, pp. 451-464, 2017.

[50] H. E. Da Silva, A. Teterina, E. M. Comelli et al., "Nonalcoholic fatty liver disease is associated with dysbiosis independent of body mass index and insulin resistance," Scientific Reports, vol. 8, no. 1, p. 1466, 2018.

[51] R. A. Koeth, B. R. Lam-Galvez, J. Kirsop et al., "l-Carnitine in omnivorous diets induces an atherogenic gut microbial pathway in humans," Journal of Clinical Investigation, vol. 129, no. 1, pp. 373-387, 2018.

[52] L. Miele, M. A. Alberelli, M. Martini et al., "Nonalcoholic fatty liver disease (NAFLD) severity is associated to a nonhemostatic contribution and proinflammatory phenotype of platelets," Translational Research, 2020.

[53] D. H. Sinn, D. Kang, S. J. Cho et al., "Lean non-alcoholic fatty liver disease and development of diabetes: a cohort study," European Journal of Endocrinology, vol. 181, no. 2, pp. 185-192, 2019.

[54] H. Yoshitaka, M. Hamaguchi, T. Kojima, T. Fukuda, A. Ohbora, and M. Fukui, "Nonoverweight nonalcoholic fatty liver disease and incident cardiovascular disease: a post hoc analysis of a cohort study," Medicine (Baltimore), vol. 96, no. 18, Article ID e6712, 2017.

[55] S. Treeprasertsuk, S. Leverage, L. A. Adams, K. D. Lindor, J. Sauver, and P. Angulo, "The Framingham risk score and heart disease in nonalcoholic fatty liver disease," Liver International, vol. 32, no. 6, pp. 945-950, 2012.

[56] F. Bonnet, A. Gastaldelli, F. Pihan-Le Bars et al., "Gammaglutamyltransferase, fatty liver index and hepatic insulin resistance are associated with incident hypertension in two longitudinal studies," Journal of Hypertension, vol. 35, no. 3, pp. 493-500, 2017.

[57] J. H. Huh, S. V. Ahn, S. B. Koh et al., "A prospective study of fatty liver index and incident hypertension: the KoGESARIRANG study," PLoS One, vol. 10, no. 11, p. e0143560, 2015.

[58] K. Lau, R. Lorbeer, R. Haring et al., "The association between fatty liver disease and blood pressure in a population-based prospective longitudinal study," Journal of Hypertension, vol. 28 , no. 9, pp. 1829-1835, 2010.

[59] J.-H. Ryoo, Y. J. Suh, H. C. Shin, Y. K. Cho, J.-M. Choi, and S. K. Park, "Clinical association between non-alcoholic fatty liver disease and the development of hypertension," Journal of Gastroenterology and Hepatology, vol. 29, no. 11, pp. 1926-1931, 2014.

[60] K.-C. Sung, S. H. Wild, and C. D. Byrne, "Development of new fatty liver, or resolution of existing fatty liver, over five years of follow-up, and risk of incident hypertension," Journal of Hepatology, vol. 60, no. 5, pp. 1040-1045, 2014.

[61] M. T. Agaç, L. Korkmaz, G. Cavusoglu et al., "Association between nonalcoholic fatty liver disease and coronary artery disease complexity in patients with acute coronary 
syndrome: a pilot study," Angiology, vol. 64, no. 8, pp. 604-608, 2013.

[62] A. K. Agarwal, V. Jain, S. Singla et al., "Prevalence of nonalcoholic fatty liver disease and its correlation with coronary risk factors in patients with type 2 diabetes," The Journal of the Association of Physicians of India, vol. 59, pp. 351-354, 2011.

[63] U. Arslan, İ. Kocaoğlu, M. Balc1, S. Duyuler, and A. Korkmaz, "The association between impaired collateral circulation and non-alcoholic fatty liver in patients with severe coronary artery disease," Journal of Cardiology, vol. 60, no. 3, pp. 210-214, 2012.

[64] W.-K. Chan, A. T.-B. Tan, S. R. Vethakkan, P.-C. Tah, A. Vijayananthan, and K.-L. Goh, "Ultrasonography-diagnosed non-alcoholic fatty liver disease is not associated with prevalent ischemic heart disease among diabetics in a multiracial Asian hospital clinic population," Clinics and Research in Hepatology and Gastroenterology, vol. 38, no. 3, pp. 284-291, 2014.

[65] C.-H. Chen, C.-K. Nien, C.-C. Yang, and Y.-H. Yeh, "Association between nonalcoholic fatty liver disease and coronary artery calcification," Digestive Diseases and Sciences, vol. 55, no. 6, pp. 1752-1760, 2010.

[66] C.-H. Chiang, C.-C. Huang, W.-L. Chan, J.-W. Chen, and H.-B. Leu, "The severity of non-alcoholic fatty liver disease correlates with high sensitivity $\mathrm{C}$-reactive protein value and is independently associated with increased cardiovascular risk in healthy population," Clinical Biochemistry, vol. 43, no. 18, pp. 1399-1404, 2010.

[67] M. Keskin, M. İ. Hayıroğlu, A. O. Uzun, T. S. Güvenç, S. Şahin, and Ö. Kozan, "Effect of nonalcoholic fatty liver disease on in-hospital and long-term outcomes in patients with ST-segment elevation myocardial infarction," The American Journal of Cardiology, vol. 120, no. 10, pp. 17201726, 2017.

[68] N. Perera, J. Indrakumar, W. V. Abeysinghe, V. Fernando, W. M. C. K. Samaraweera, and J. S. Lawrence, "Non alcoholic fatty liver disease increases the mortality from acute coronary syndrome: an observational study from Sri Lanka," BMC Cardiovasc Disord, vol. 16, p. 37, 2016.

[69] R. Wu, F. Hou, X. Wang et al., "Nonalcoholic fatty liver disease and coronary artery calcification in a northern Chinese population: a cross sectional study," Scientific Report, vol. 7, no. 1, p. 9933, 2017.

[70] D. Pastori, A. Sciacqua, R. Marcucci et al., "Prevalence and impact of nonalcoholic fatty liver disease in atrial fibrillation," Mayo Clinic Proceedings, vol. 95, no. 3, pp. 513-520, 2020.

[71] M. Alexander, A. K. Loomis, J. van der Lei et al., "Nonalcoholic fatty liver disease and risk of incident acute myocardial infarction and stroke: findings from matched cohort study of 18 million European adults," BMJ, p. 15367, 2019.

[72] Y. Liu, G.-C. Zhong, H.-Y. Tan, F.-B. Hao, and J.-J. Hu, "Nonalcoholic fatty liver disease and mortality from all causes, cardiovascular disease, and cancer: a meta-analysis," Scientific Reports, vol. 9, no. 1, 2019.

[73] S. Wu, F. Wu, Y. Ding, J. Hou, J. Bi, and Z. Zhang, "Association of non-alcoholic fatty liver disease with major adverse cardiovascular events: A systematic review and meta-analysis," Scientific Reports, vol. 6, no. 1, 2016.

[74] C.-K. Wu, S.-C. Yang, C.-M. Liang et al., "The role of antibiotics in upper gastrointestinal bleeding among cirrhotic patients without major complications after endoscopic hemostasis," European Journal of Gastroenterology \& Hepatology, 2019.

[75] Z. M. Younossi, A. B. Koenig, D. Abdelatif, Y. Fazel, L. Henry, and M. Wymer, "Global epidemiology of nonalcoholic fatty liver disease-Meta-analytic assessment of prevalence, incidence, and outcomes," Hepatology, vol. 64, no. 1, pp. 73-84, 2016.

[76] E. Vilar-Gomez, L. Calzadilla-Bertot, V. Wai-Sun Wong et al., "Fibrosis severity as a determinant of cause-specific mortality in patients with advanced nonalcoholic fatty liver disease: a multi-national cohort study," Gastroenterology, vol. 155, no. 2, pp. 443-457, 2018.

[77] C. R. Wong and J. K. Lim, "The association between nonalcoholic fatty liver disease and cardiovascular disease outcomes," Clinical Liver Disease, vol. 12, no. 2, pp. 39-44, 2018.

[78] N. Stefan, H.-U. Häring, and K. Cusi, "Non-alcoholic fatty liver disease: causes, diagnosis, cardiometabolic consequences, and treatment strategies," The Lancet Diabetes \& Endocrinology, vol. 7, no. 4, pp. 313-324, 2019.

[79] D. Kim, W. R. Kim, H. J. Kim, and T. M. Therneau, “Association between noninvasive fibrosis markers and mortality among adults with nonalcoholic fatty liver disease in the United States," Hepatology, vol. 57, no. 4, pp. 1357-1365, 2013.

[80] Y. S. Khalid, N. R. Dasu, H. Suga et al., "Increased cardiovascular events and mortality in females with NAFLD: a meta-analysis," American Journal of Cardiovascular Disease, vol. 10, no. 3, pp. 258-271, 2020.

[81] G. Musso, R. Gambino, M. Cassader, and G. Pagano, "Metaanalysis: natural history of non-alcoholic fatty liver disease (NAFLD) and diagnostic accuracy of non-invasive tests for liver disease severity," Annals of Medicine, vol. 43, no. 8, pp. 617-649, 2011.

[82] M. Stepanova and Z. M. Younossi, "Independent association between nonalcoholic fatty liver disease and cardiovascular disease in the US population," Clinical Gastroenterology and Hepatology, vol. 10, no. 6, pp. 646-650, 2012.

[83] M. Lazo, R. Hernaez, S. Bonekamp et al., "Non-alcoholic fatty liver disease and mortality among US adults: prospective cohort study," BMJ, vol. 343, no. nov18 2, p. d6891, 2011.

[84] Y.-C. Lin, "Sonographic fatty liver, overweight and ischemic heart disease," World Journal of Gastroenterology, vol. 11, no. 31, p. 4838, 2005.

[85] A. Fraser, R. Harris, N. Sattar, S. Ebrahim, G. D. Smith, and D. A. Lawlor, "Gamma-Glutamyltransferase is associated with incident vascular events independently of alcohol intake," Arteriosclerosis, Thrombosis, and Vascular Biology, vol. 27, no. 12, pp. 2729-2735, 2007.

[86] D. H. Sinn, D. Kang, Y. Chang et al., "Non-alcoholic fatty liver disease and progression of coronary artery calcium score: a retrospective cohort study," Gut, vol. 66, no. 2, pp. 323-329, 2017.

[87] Y. K. Cho, Y. M. Kang, J. H. Yoo et al., "The impact of nonalcoholic fatty liver disease and metabolic syndrome on the progression of coronary artery calcification," Scientific Reports, vol. 8, no. 1, 2018.

[88] C. Gill, K. P. Vatcheva, J.-J. Pan et al., "Frequency of nonalcoholic fatty liver disease and subclinical atherosclerosis among young Mexican Americans," The American Journal of Cardiology, vol. 119, no. 11, pp. 1717-1722, 2017.

[89] Y. Y. Zhou, X. D. Zhou, S. J. Wu et al., "Nonalcoholic fatty liver disease contributes to subclinical atherosclerosis: a 
systematic review and meta-analysis," Hepatology Communications, vol. 2, no. 4, pp. 376-392, 2018.

[90] J. Ampuero, R. Gallego-Durán, and M. Romero-Gómez, "Association of NAFLD with subclinical atherosclerosis and coronary-artery disease: meta-analysis," Revista Espanola de Enfermedades Digestivas, vol. 107, no. 1, pp. 10-16, 2015.

[91] Y. Chang, S. Ryu, K.-C. Sung et al., "Alcoholic and nonalcoholic fatty liver disease and associations with coronary artery calcification: evidence from the Kangbuk Samsung Health Study," Gut, vol. 68, no. 9, pp. 1667-1675, 2019.

[92] E. Oni, M. J. Budoff, I. Zeb et al., "Nonalcoholic fatty liver disease is associated with arterial distensibility and carotid intima-media thickness: (from the multi-ethnic study of atherosclerosis)," The American Journal of Cardiology, vol. 124, no. 4, pp. 534-538, 2019.

[93] R. Zheng, Z. Du, M. Wang, Y. Mao, and W. Mao, "A longitudinal epidemiological study on the triglyceride and glucose index and the incident nonalcoholic fatty liver disease," Lipids Health Disease, vol. 17, no. 1, p. 262, 2018.

[94] J. Zheng, Y. Zhou, K. Zhang et al., "Association between nonalcoholic fatty liver disease and subclinical atherosclerosis: a cross-sectional study on population over 40 years old," BMC Cardiovascular Disorder, vol. 18, no. 1, 2018.

[95] Z. Xin, Y. Zhu, S. Wang et al., "Associations of subclinical atherosclerosis with nonalcoholic fatty liver disease and fibrosis assessed by non-invasive score," Liver International, vol. 40, no. 4, pp. 806-814, 2020.

[96] B. K. Koo, M. A. Allison, M. H. Criqui, J. O. Denenberg, and C. M. Wright, "The association between liver fat and systemic calcified atherosclerosis," Journal of Vascular Surgery, vol. 71, no. 1, pp. 204-211, 2020.

[97] J. Narayan, H. S. Das, P. Nath et al., "Endothelial dysfunction, a marker of atherosclerosis, is independent of metabolic syndrome in NAFLD patients," International Journal of Hepatology, vol. 2020, pp. 1-6, Article ID 1825142, 2020.

[98] S. Akabame, M. Hamaguchi, K.-i. Tomiyasu et al., "Evaluation of vulnerable coronary plaques and non-alcoholic fatty liver disease (NAFLD) by 64-detector multislice computed tomography (MSCT)," Circulation Journal, vol. 72, no. 4, pp. 618-625, 2007.

[99] S. Bonapace, F. Valbusa, L. Bertolini et al., "Nonalcoholic fatty liver disease is associated with aortic valve sclerosis in patients with type 2 diabetes mellitus. Sookoian SC," PLoS One, vol. 9, no. 2, Article ID e88371, 2014.

[100] G. Targher, C. D. Byrne, and H. Tilg, "NAFLD and increased risk of cardiovascular disease: clinical associations, pathophysiological mechanisms and pharmacological implications," Gut, vol. 69, no. 9, pp. 1691-1705, 2020.

[101] G. Targher, F. Valbusa, S. Bonapace et al., "Non-alcoholic fatty liver disease is associated with an increased incidence of atrial fibrillation in patients with type 2 diabetes," PloS One, vol. 8, no. 2, Article ID e57183, 2013.

[102] G. Targher, F. Valbusa, S. Bonapace et al., "Association of nonalcoholic fatty liver disease with QTc interval in patients with type 2 diabetes," Nutrition, Metabolism and Cardiovascular Diseases, vol. 24, no. 6, pp. 663-669, 2014.

[103] A. J. Käräjämäki, O. P. Pätsi, M. Savolainen, Y. A. Kesäniemi, H. Huikuri, and O. Ukkola, "Non-alcoholic fatty liver disease as a predictor of atrial fibrillation in middle-aged population (OPERA study)," PLoS One, vol. 10, no. 11, p. e0142937, 2015.

[104] A. Mantovani, A. Rigamonti, S. Bonapace et al., "Nonalcoholic fatty liver disease is associated with ventricular arrhythmias in patients with type 2 diabetes referred for clinically indicated 24-hour holter monitoring," Diabetes Care, vol. 39, no. 8, pp. 1416-1423, 2016.

[105] R. Carnagarin, V. Matthews, M. T. K. Zaldivia, K. Peter, and M. P. Schlaich, "The bidirectional interaction between the sympathetic nervous system and immune mechanisms in the pathogenesis of hypertension," British Journal of Pharmacology, vol. 176, no. 12, pp. 1839-1852, 2019.

[106] Y.-C. Zhao, G.-J. Zhao, Z. Chen, Z.-G. She, J. Cai, and H. Li, "Nonalcoholic fatty liver disease," Hypertension, vol. 75, no. 2, pp. 275-284, 2020.

[107] R. Lorbeer, C. Bayerl, S. Auweter et al., "Association between MRI-derived hepatic fat fraction and blood pressure in participants without history of cardiovascular disease," Journal of Hypertension, vol. 35, no. 4, pp. 737-744, 2017.

[108] J. P. Ong, A. Pitts, and Z. M. Younossi, "Increased overall mortality and liver-related mortality in non-alcoholic fatty liver disease," Journal of Hepatology, vol. 49, no. 4, pp. 608-612, 2008.

[109] J. M. Paik, L. Henry, L. De Avila, E. Younossi, A. Racila, and Z. M. Younossi, "Mortality related to nonalcoholic fatty liver disease is increasing in the United States," Hepatology Communications, vol. 3, no. 11, pp. 1459-1471, 2019.

[110] D. H. Sinn, D. Kang, Y. Chang et al., "Non-alcoholic fatty liver disease and the incidence of myocardial infarction: a cohort study," Journal of Gastroenterology and Hepatology, vol. 35, no. 5, pp. 833-839, 2020.

[111] J. B. Henson, T. G. Simon, A. Kaplan, S. Osganian, R. Masia, and K. E. Corey, "Advanced fibrosis is associated with incident cardiovascular disease in patients with non-alcoholic fatty liver disease," Alimentary Pharmacology \& Therapeutics, vol. 51, no. 7, pp. 728-736, 2020. 